\title{
Recipe for Successful Collaborative
}

\section{Corequisites}

\author{
Mary Orlando, San Jacinto College \\ Karen Hattaway, San Jacinto College
}

\section{ABSTRACT}

This paper describes a corequisite pairing of Integrated Reading and Writing (INRW) and Humanities (HUMA) 1301 taught at San Jacinto College North in Houston, Texas. The authors describe their planning process, which combined course learning outcomes with cognitive theory and best-practice resources for effective teaching. These complementary courses provided students with contextualized learning activities designed to develop critical thinking and communication skills as students focused on cultural history to understand how human communities create monster stories to identify their fears and characterize the heroic figures who come to their rescue. The article includes sample content units and student activities and provides strategic insight into a process of integrating best practices and cognitive psychology with class planning focused on required learning outcomes.

evelopmental education courses in Texas community colleges changed from providing layered developmental education requiring students to complete as many as six courses in reading and writing to a streamlined structure of limited stand-alone courses and a growing number of corequisite courses. In 2015, fewer than $50 \%$ of college-preparatory students completed a transfercredit course within 2 years of their initial enrollment in developmental programs and by 2019 the record was not better because The Texas Higher Education Coordinating Board (THECB, 2019) reported that "only $44 \%$ to $64 \%$ meet readiness standards within two years, and about $28 \%$ to $41 \%$ go on to complete a college-level course" (p. 16). In response to those results, the Texas Legislature passed House Bill 2223 in 2017. This legislation significantly reshaped Texas college-preparatory education by setting required timelines for changes in course design.

Rather than thinking of college-preparatory courses as stand-alone components of an instructional program separate from degree-bearing programs, Texas educators re-imagined developmental courses as corequisites to transfer-credit classes. First, HB 2223 reduced stand-alone developmental education sources offered. The plan required that $25 \%$ of developmental students be enrolled in a corequisite model in Spring 2018, in Fall 2019 50\% would be enrolled in the new course organization, and $75 \%$ in Fall 2020 (THECB, 2018). Texas community-college leaders and faculty developed several options to increase student enrollment in credit-bearing courses. One option combines a shortened version of a developmental course added to a credit bearing course. This NonCourse Based Option (NCBO) generally provides justin-time instruction to fill in gaps of knowledge and skills that limit student progress in the credit-bearing course. Adding 1 or 2 hours of instruction to each week's class schedule, NCBOs extend a traditional course like English Composition I to include tutorial experiences designed to address weaknesses in student writing and reading skills.

Current research supports pairing integrated reading and writing (INRW) with English to enhance students' progress. Kuehner and Hurley (2019) conducted a 2-year study in which they measured developmental education students' success in their accelerated IRW and English courses during the Fall and Spring semesters of 2014 and 2015. Kuehner and Hurley determined that more students completed English Composition I in the accelerated program than students in traditional developmental courses and earned higher GPAs. However, INRW can be successful if paired with other college-level courses. The purpose of this paper is to discuss an alternative option in which college preparatory students simultaneously enroll in an INRW course and a credit Humanities (HUMA) course as an alternative to the traditional English composition (COMP) credit bearing course. This academic strategy provides students legitimate instruction in basic skills of reading, writing, and critical thinking and expedites student progress through the credit curriculum. The paper focuses on our initial planning, course delivery, and results in our INRW/HUMA course pairings. 


\section{Initial Planning}

We began by making assumptions about developmental courses and students who are assigned to developmental reading and writing based on our prior teaching experiences, our knowledge of course design and successful instructional practices grounded in research.

\section{Assumptions About Developmental Courses and Students}

The central innovation of our plan was to value the contributions the original design of INRW. We agreed that, while state legislation addressed a serious issue in the progress of students through a complex developmental curriculum, the legislators missed the intrinsic value of developmental education and the importance of this component of Texas higher education to establishing broad-based, easily expanded, and effective programs ensuring that students who are disadvantaged have genuine access and equity to higher education. We agreed that, on the one hand simplifying the process of developmental education was important so that the curriculum itself facilitated rather than blocked student progress toward graduation. At the same time, we also recognized that some developmental students come to college with significant gaps in their cultural background that often limit their academic success. Without some contextual information connecting history and culture, students have no schema to help them organize information from core courses.

\section{Assumptions About Course Design}

Rather than considering the INRW course as a tutorial for the HUMA students, our design focused on realizing the objectives of both courses. We based our assumption on Stanny's (2016) understanding of the purpose of learning outcomes: "The most explicit goal [of student learning objectives (SLOs)] is to describe the unique knowledge, skills, and abilities students acquire as they complete courses and degree programs. Two less explicit goals are to support the design of curriculum and align learning goals with learning activities and assessments" (p. 1). We organized our planning into two phases: analyzing learning outcomes and emphasizing structured learning.

Managing learning outcomes. The first phase of our planning was to analyze state mandated SLO's for both course in order to establish a common ground on which to begin developing both courses. The INRW 0301 and 0302 courses address the same ten SLOs, and the HUMA 1301 course addresses five
SLOs as well as four general education outcomes that emphasize critical thinking and communication skills in order to support the habits of mind that enable students to become life-long learners who contribute to society. We developed a plan emphasizing SLO's and integrated the general education outcomes in learning events and assignments that encouraged students to behave as developing learners. We organized the SLOs for both courses so that the complementary connection between the courses was clear so that students could understand how one course supported the other. Figure 1 shows the SLOs for both courses and the complementary connections we developed to link them.

\section{Emphasizing learning taxonomies.}

Recognizing the importance of providing developmental students with opportunities to understand their own learning processes, we agreed to emphasize more than one learning taxonomy. Thus, our combined courses would provide students with many strategies by which they could become self-sufficient learners. We recognized that developing the learning outcomes required also that we consider the learning processes required for success in each course. While course SLOs provide goals for instruction, they do not describe the learning processes required to achieve the goals. When considered as one learning experience, the two courses emphasized both Bloom's (1956) and Marzano and Kendall's (2008) taxonomies of learning.

We recognized that many of the INRW SLOs reflected the Bloom's (1956) taxonomy of levels of understanding in the verbs that were components of the course objectives: understanding, comprehending, analyzing, evaluating, and creating (as cited in Stanny, 2016). On the other hand, the HUMA 1301 SLOs centered on students' gaining an in-depth understanding of a variety of texts and learning how these texts reflected their times. Thus, learning in the HUMA course emphasized Marzano and Kendall's (2008) thinking that students become self-aware learners by retrieving information, identifying patterns in this information, and then using this knowledge to create new ideas. Our understanding was influenced by Stanny's observation that "Introductory courses might include SLOs that describe higher-order thinking skills because these courses create opportunities for students to develop and practice skills expected at more advanced levels" (p. 9). The INRW and HUMA SLOs illustrate this connection (see Figure 1). 


\begin{tabular}{|c|c|c|}
\hline INRW SLO's & HUMA 1301 SLO’s & $\begin{array}{l}\text { Complementary Connection in "Monster" } \\
\text { Course }\end{array}$ \\
\hline $\begin{array}{l}\text { - Locate explicit textual information, draw complex } \\
\text { inferences, and describe, analyze, and evaluate } \\
\text { the information within and across multiple texts of } \\
\text { varying lengths. } \\
\text { - Comprehend and use vocabulary effectively in oral } \\
\text { communication, reading, and writing. } \\
\text { - Identify and analyze the audience, purpose, and } \\
\text { message across a variety of texts. } \\
\text { - Describe and apply insights gained from reading and } \\
\text { writing a variety of texts. } \\
\text { - Compose a variety of texts that demonstrate reading } \\
\text { comprehension, clear focus, logical development } \\
\text { of ideas, and use of appropriate language that } \\
\text { advance the writer's purpose. } \\
\text { - Determine and use effective approaches and } \\
\text { rhetorical strategies for given reading and } \\
\text { writing situations. } \\
\text { - Generate ideas and gather information relevant } \\
\text { to the topic and purpose, incorporating the } \\
\text { ideas and words of other writers in student } \\
\text { writing using established strategies. } \\
\text { - Evaluate relevance and quality of ideas and } \\
\text { information in recognizing, formulating, and } \\
\text { developing a claim. } \\
\text { - Develop and use effective reading and revision } \\
\text { strategies to strengthen the writer's ability to } \\
\text { compose college-level writing assignments. } \\
\text { English in reading and writing. }\end{array}$ & $\begin{array}{l}\text { - Demonstrate awareness of the scope and variety of } \\
\text { works in the arts and humanities. } \\
\text { - Articulate how these works express the values of the } \\
\text { individual and society within an historical and social } \\
\text { context. } \\
\text { - Articulate an informed personal response and critically } \\
\text { analyze works in the arts and humanities. } \\
\text { - Demonstrate knowledge and understanding of the } \\
\text { influence of literature, philosophy, and the arts on } \\
\text { cultural experiences. } \\
\text { - Articulate an informed personal response } \\
\text { and critically analyze works in the arts and } \\
\text { humanities. } \\
\text { - Demonstrate an awareness of the creative } \\
\text { process and why humans create. }\end{array}$ & 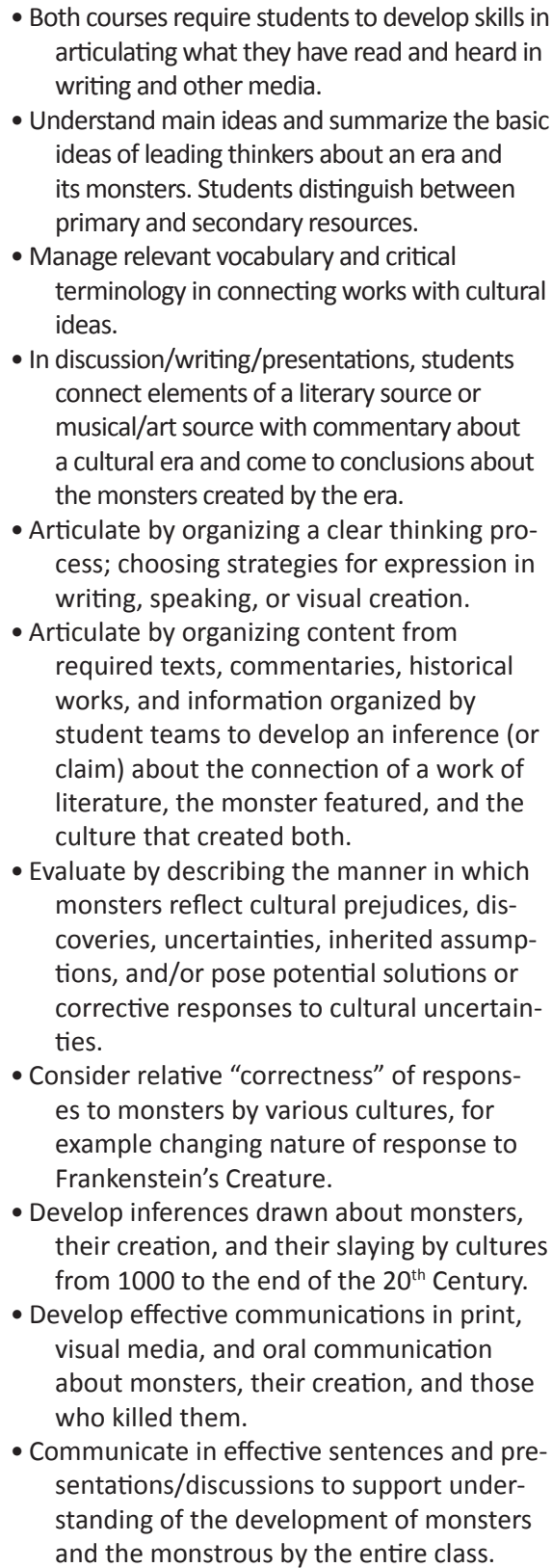 \\
\hline
\end{tabular}

Figure 1. Developing Composite Learning Outcomes

Course content design. We developed consistent commonalities and themes that allowed students to make deep connections between their INRW/ HUMA courses. Cho and Trent (2005) recommended that instructors "lend themselves to inquiring into the ways understanding is thoroughly unearthed in each subject area" (p. 111). We created complementary course units to teach similar concepts using different course material; Figure 2 provides information about sample course content units and illustrates the complementary nature of the two learning experiences for our students. While the overarching course units were the same, the skills addressed in each unit differed in the INRW/HUMA courses. For example, in the HUMA course, students discussed and analyzed Shelley's Frankenstein novel that illustrates the cultural fears of the transition from Romantic to Victorian thinking. In the INRW course, students discussed and analyzed cultural values and Gothic literature elements in Walpole's Castle of Otranto. 


\begin{tabular}{|c|c|c|c|}
\hline Focus & HUMA 1301 & INRW 0301 & INRW 0302 \\
\hline $\begin{array}{l}\text { Overview of } \\
\text { discussion of } \\
\text { cultures }\end{array}$ & Texas Culture & American Culture & $\begin{array}{l}\text { American Cul- } \\
\text { ture }\end{array}$ \\
\hline Anglo-Saxon & $\begin{array}{l}\text { - Grendel \& } \\
\text { Beowulf } \\
\text { - The Thirteenth } \\
\text { Warrior (1990 } \\
\text { film) }\end{array}$ & $\begin{array}{l}\text { - The Wife's Lament } \\
\text { (two versions) }\end{array}$ & $\begin{array}{l}\text { - The Seafarer } \\
\text { - The Wanderer }\end{array}$ \\
\hline $\begin{array}{l}\text { The Hairy } \\
\text { Beasts }\end{array}$ & $\begin{array}{l}\text { - Little Red Rid- } \\
\text { ing Hood (The } \\
\text { Brothers Grimm } \\
\text { \& Perrault } \\
\text { versions) } \\
\text { - The Three } \\
\text { Little Pigs } \\
\text { - B'rer Rabbit \& } \\
\text { B'rer Fox } \\
\text { - The Tale of } \\
\text { Jemima Puddle } \\
\text { Duck (Potter) }\end{array}$ & $\begin{array}{l}\text { - Lon Po Po } \\
\text { (Young, trans.) } \\
\text { - The True Story } \\
\text { of the Three Little } \\
\text { Pigs (Scieszka) } \\
\text { - Cinderella (The } \\
\text { Brothers Grimm \& } \\
\text { Perrault versions) }\end{array}$ & $\begin{array}{l}\text { - Little Red Cap } \\
\text { (Duffy) } \\
\text { - Lon Po Po } \\
\text { (Young, trans.) } \\
\text { - The True Story } \\
\text { of the Three Little } \\
\text { Pigs (Sciesza) } \\
\text { - Cinderella (The } \\
\text { Brothers Grimm \& } \\
\text { Perrault versions) }\end{array}$ \\
\hline $\begin{array}{l}\text { Gothic } \\
\text { Literature }\end{array}$ & $\begin{array}{l}\text { The undead } \\
\text { - Frankenstein } \\
\text { (Shelley) } \\
\text { - Frankenstein } \\
\text { (1930 film) } \\
\text { - Dracula } \\
\text { (Stoker) }\end{array}$ & $\begin{array}{l}\text { - The Castle of } \\
\text { Otranto (Walpole) }\end{array}$ & $\begin{array}{l}\text { - The Castle of } \\
\text { Otranto (Walpole) }\end{array}$ \\
\hline
\end{tabular}

Figure 2. Course Units

Our parallel units provided an opportunity to explore broad common concepts. In the INRW course, students learned about universal themes and analyzed Anglo-Saxon poems for these themes. In the HUMA courses, the students studied Beowulf while analyzing how Anglo-Saxons understood threats to their survival embodied in Grendel. In both classes, students analyzed and discussed how these themes still apply to today's society, but in different shapes. Additionally, students in the HUMA course analyzed a 1990's reinterpretation of Beowulf in the film The Thirteenth Warrior. Thus, multiple lenses provided students with a rich understanding of each theme and allowed us the flexibility to 'unearth' any content that naturally developed during their courses as we developed each unit. The two courses extended content to provide students with additional learning experiences to push beyond their existing knowledge to gain practice (and thus confidence) in creating new perspectives about their learning.

\section{Teaching Practice}

As we developed course content units and learning activities, we considered Perkins's (2009) idea that learning is the development of complex skills by practicing foundational skills. Perkins argued that understanding the "small games" or component skills within the "big game" of the course and its general outcomes enables instructors to create scaffolded learning experiences that emphasize basic skills in the development of broader critical-thinking capacities. In Making Learning Whole: How Seven Principles of
Teaching Can Transform Education (2009), Perkins argued that scaffolded experiences support student motivation to continue with the "big game" of the entire course. Instructors enable students to go beyond the "disorientation" of a new learning experience when they provide students with "some version of the whole game close to the beginning" (p. 9). This strategy supports Marzano and Kendall's idea that students' self-efficacy and motivation grow when they recognize that they can master a task and that the task is worth doing (p. 148-149). The recursive nature of the HUMA/ INRW courses provides an ideal setting for student mastery. Our courses began with the "small game" or component skills for understanding culture, focusing on local monsters in HUMA and on American culture in INRW, and developing to consider broader themes.

Part of our planning also included a review of best practices in teaching and a review of cognitive theory resources. Piaget (1952) argued that effective learning involves creating patterns. As students connect new experiences and bits of information to these frameworks, they create new knowledge associated with higher expectations for success. As Hepner (1996) suggested students need to see a connection between the course content and their world in order to expand that learning and apply it to a broader perspective. We were also influenced by Rosenblatt's research on the relationship of reading and knowing, particularly her emphasis on Bartlett's (1932) concept of the "'constructive character of remembering" (cited in Rosenblatt, 2005, p. 9). The INRW and HUMA courses construct informational and cultural schema that students do not bring to a college campus. We immersed students in cultural history and interpretation of human experiences. We created learning activities that provided the vocabulary and background necessary for students to talk and write about new information.

\section{Course Delivery}

We taught two sections of the HUMA/INRW corequisite at San Jacinto College North in the Spring 2019 semester. We paid attention to our student audience, both in terms of their academic backgrounds and in terms of the attitudes and experiences they brought into our classes. Our goals were to make connections between their experience and the early monsters we could study so they could establish a frame of reference for the entire term. At the same time, we recognized that students in developmental classes are very aware of the labels attached to them, that they are more ready to stop participating in their courses than students admitted via traditional standards.

\section{Academic Background}

The communities of students in our classes reflected TSI scores established by San Jacinto College 
and the demographics of our college service area. One section connected HUMA 1301 with INRW 0301, and the other connected HUMA 1301 with INRW 0302. Students in the INRW 0301 course scored lower on the TSI than the students in the INRW 0302. Table 1 illustrates the TSI placement cut scores for the Spring 2019 semester at San Jacinto College.

Table 1

TSI Cut Scores Spring 2019

\begin{tabular}{|c|c|c|c|c|}
\hline & $\begin{array}{l}\text { Reading } \\
\text { Score }\end{array}$ & $\begin{array}{c}\text { Reading } \\
\text { Skill }\end{array}$ & Writing Score & Writing Skill \\
\hline $\begin{array}{l}\text { INRW } \\
0301\end{array}$ & $342-346$ & Level 4 & 350-356 (no essay) & Level 4 \\
\hline $\begin{array}{l}\text { INRW } \\
0302\end{array}$ & $347-350$ & Level 6 & 357-362 (no essay) & Level 6 \\
\hline $\begin{array}{l}\text { College } \\
\text { Level }\end{array}$ & $\begin{array}{l}351 \text { or } \\
\text { higher }\end{array}$ & Level 7 & $\begin{array}{c}5 \text { on the essay OR } 4 \\
\text { on the essay \& } 340 \\
\text { or higher on the } \\
\text { multiple choice. }\end{array}$ & $\begin{array}{l}\text { Level } 7 \text { and } \\
\text { college ready in } \\
\text { reading }\end{array}$ \\
\hline
\end{tabular}

Students enrolled in the INRW/HUMA corequisite sections reflected the demographics of the North Campus: $56.3 \%$ female (Campus 58.5\%); 75\% Hispanic (Campus 67\%); and 93.8\% 18-24 years old (Campus 43.9\%). The 24 students were divided evenly into INRW 0301/HUMA and INRW 0302/ HUMA. Four of the students were developmental education students who had failed their INRW course previously. Three of the repeaters failed their previous INRW course because of low attendance and participation, the reason the fourth student failed previously is unknown. Two students enrolled in the course pairings were older than the traditional 18-25 year-old college freshmen.

\section{Student Attitudes and Experience}

Instructors in both courses emphasized deliberate personal development of students. We drew our information from both Marzano and Kendall (2008) and from Perry (1970/1999). Perry's theory of learning identified many beginning college students as novice learners. These students have dualistic beliefs that learning focuses on right or wrong and the challenge to them is to discover what is "right" and then never think beyond what the lecture and content materials offer.

Often, students in developmental classes enter college with a feeling that they are imposters and do not deserve to be there. There are several internal factors that influence students' imposter syndrome. Students fear that their instructors would find out about their inabilities and embarrass them for it; they do not believe in their skills, despite evidence that may illustrate their proficiency; and they doubt their abilities prior to even beginning the assignment or course. External factors such as comparison of their capabilities to others and performance feedback from instructors could further perpetuate or alleviate the imposter feeling (Lane, 2015). Experience helps diminish the students' imposter feelings; the more experience the students received, the more confident they became in their abilities (Lane, 2015). INRW students feel apprehensive about college and truly believe they are imposters since the TSI score has clearly indicated they are not college ready. INRW repeaters have their prior failures as another external factor negatively influencing their self-perception.

With this knowledge, we determined the beginning point for our courses We decided that both INRW/HUMA students should begin by discussing current culture. We could demonstrate the relevance of the course focus to contemporary life and showcase the conversational skills students brought to class with them. This built our students' confidence as they are knowledgeable about current culture and can use this knowledge to build upon throughout the semester. Our first focus was on zombies, emphasizing films and parts of novels and considering the various use of the term "zombie" to identify those whom a overpowering and manipulative culture made into unthinking consumers.

\section{Persistence and Retrieval}

Both instructors encouraged the students to acknowledge their experiences by identifying various elements of culture familiar to them and using these elements of personal schema to expand their thinking. Initial class discussion in the HUMA class, for example, considered the "distracted driver" as someone unable to maintain interest in physically present day-to-day life, choosing rather to "live" in the pixelated world of the Internet. Students in both sections began to construct new frameworks by building on their existing knowledge; in the INRW course, students discussed and analyzed their firsthand experiences in American cultural norms and fears. We discussed the rationale behind these fears, and then we extended the discussion to monsters and the cultural fears these monsters reflect. The students worked towards abstract thinking by connecting their external knowledge and experience to in-class topics and examples. This experience reflects Marzano and Kendall's Designing \& Assessing Educational Objections: Applying the New Taxonomy (2008) as students specified, from their retrieval of information, and then classified the information they gathered to discover generalizations about the monster tales and the people who sustained them. These foundational activities helped establish fundamental groundwork in the courses, as we would circle back to norms, breaking norms, fears, reasons for these fears, and monsters for each unit.

Our plan supports student persistence through active engagement (Pruett \& Absher, 2015). 
To increase active engagement and improve our students' speaking and listening skills, both courses provided students with class discussions, projects, and presentations. In the HUMA class, students practiced whole class discussions with question stems, which allowed students to engage in structured academic conversations and enhance their understanding of the culture depicted in the texts. As Seidlitz and Perryman (2011) explained, "structured conversations ensure that students get an exposure to academic vocabulary and a chance to use new terms in an authentic context" ( $p$. 45). Often, students in developmental education do not know how to articulate their thinking or develop questions to increase their learning. This inability can hinder developmental students in their college pursuit.

Inspired by Marzano and Kendall's (2008), the instructors encouraged the students in both INRW and HUMA courses to be self-aware in their development as thinkers and writers. Students immediately began to use vocabulary appropriate to a study of human culture: values, social systems, class conflicts, as well as the "learning vocabulary" central to the MarzanoKendall Taxonomy, which provide action terms for the processes of learning. The students skills expanded from retrieving information when they "recalled, recognized ideas, and executed" in various activities as they adapted what they remembered about historical events, cultural assumptions, literary genres, and writing and discussion strategies (Marzano \& Kendall, 2008, p. 4). Students "integrated and symbolized" their knowledge through visual representations, reflective writings, inclass presentations.

When studentsin developmental education classes receive difficult texts, they tend to shut down. They begin to focus on gathering a basic understanding of each sentence instead of looking at the text as a whole. "If 'remedial' students are to survive in the world of academy, they cannot do so through lower level drill and practice. They must learn to read analytically..." (Lesley, 2003, p. 84). Humanities is a reading intensive course that requires students to move beyond basic reading comprehension, which can be a challenge for students placed in developmental education. To circumvent this feeling of inadequacy, the INRW instructor taught the students to use their texts to prove their interpretations. Students learned realistic and substantial support in the INRW course, a process that could not occur if the INRW section were seen as providing tutorial experiences only. As Bartholomae and Petrosky (1986) stated, "A 'proof' is what a text offers; it is something a reader finds there. It is also, however, that which a reader brings to the text..." (p. 27). For example, the INRW instructor provided various interpretations of Anglo-Saxon texts to illustrate the importance of proof to support interpretations. The students developed their own understanding and perspective without the fear of having "the right answer and transferred this skill into the HUMA discussion of Beowulf and the Buliwyf character in The Thirteenth Warrior.

\section{Results}

Our assessments led us to develop many points of view. We could observe our students' skills through our college's assessment of core-curriculum outcomes. As is always the case with preliminary research focused on emerging approaches, our analysis of success had limitations, but we developed new ideas about how to strength the next iteration of the course combination in Fall 2019.

\section{Core Curriculum Outcomes}

As a core-curriculum course, San Jacinto College requires curriculum assessment in HUMA1301 in the form of a Signature Assignment that illustrates the students' mastery of content and corecurriculum learning outcomes. HUMA 1301 students are required to develop an artifact that illustrates their individual and creative responses to the content emphasis of the course. For this HUMA 1301, the artifact was the development of The Book of the Monster. This very intensive writing assignment required the students to develop their characters, settings, establish their monsters within a realistic realm of fiction and reflect on their creations.

This assignment extended across both courses to as students could find inspiration from any of the assigned readings or class notes in both their INRW and HUMA courses. The students could find inspiration from real-life "monsters" such as serial killers, or they could create a monster inspired from course readings. The requirement had potential to be a daunting task as INRW students are often not confident in their writing capabilities. Camfield's (2016) research revealed that instructors must develop a relationship with their students as this "positions the instructor as a mediator between what it is the writers want to say and the academic audience with which they communicate" (p. 10) To circumvent students' fears of writing as a 
daunting task, the INRW instructor mediated between the students and their academic audience through scaffold low-stakes writing assignments that build into larger high-stakes writing assignments. In the INRW courses, students brainstormed prior to writing their monster books, created a rough outline of their book, and began to develop their book one chapter at a time. Students peer reviewed their work and revised their chapters prior to compiling their final products. Students also analyzed how their Book of the Monster illustrated a cultural fear of its time. To ensure clear expectations and grading consistency, both instructors collaborated on the various chapter requirements and rubrics. Students finalized their Book of the Monster chapters and combined them together for submission in the HUMA course.

\section{Limitations}

This research centers on only the INRW/HUMA course pairings, which does not allow for generalization across disciplines. We did not begin our corequisite courses with a study of its success in mind, as such; we did not collect essential student data needed to measure overall success of our corequisite courses. The college no longer offers INRW 0301/HUMA 1301 course pairings, so we are only teaching INRW 0302/HUMA 1301 corequisite course in Fall 2019. Student enrollment for Spring 2019 courses was considerably smaller, making the applicability of our results extremely limited. More research is needed in assessing corequisite courses and overall student success. This research is merely a snapshot on a collaborative idea two instructors had. It could benefit from longitudinal analysis of student success in the INRW/HUMA corequisite courses.

\section{Reflection}

The simplest solution to address HB 2223's mandate is to establish many INRW and English corequisite courses but limiting corequisites to English classes pairings is not necessary. Saxon, Martirosyan, and Vick (2016) explained the various struggles corequisite instructors encounter, such as establishing a balance of reading and writing assignments, managing their time for course content, preparing to teach a corequisite course, locating appropriate course materials, and reducing redundancy. While Saxon et. al also noted that paired courses possess unique challenges, such as course sequencing and grading consistency, the benefit of a paired course is that it allows both instructors to collaborate and develop courses that offer an alternative to their traditional course models. Additionally, Hepner's (1996) research in interdisciplinary classes determined that faculty partners worked harder on their paired courses than their traditional courses and their collaboration energized the instructors.

We determined that pairing INRW and HUMA 1301 contextualizes basic-skill development and allows students to expand their cultural awareness through intensive reading, oral discussion, and writing activities.
HUMA courses taught at San Jacinto College address a variety of themes for the specific content of each course section, but all address the SLOs in the course syllabus. The central idea of the HUMA component of our corequisite was that cultures create monster stories to identify threats to the safety of the community. Students in INRW 0301 section showed remarkably stronger persistence and academic success than did those in the INRW 0302 section. The INRW 0301 students exhibited more academic growth (measured by complexity of thinking) than the higher-level INRW 0302 students. There could be various reasons for this, such as more overall attendance, the reward of college credit easier to attain, or the arbitrary TSI cut score for placement in INRW 0301 and 0302. Students in the HUMA/INRW 0301 could articulate abstract connections and developed astute critical thinking skills, while the HUMA/INRW 0302 group struggled in developing abstract connections among cultures and understanding the relationship of monster-slayers to the cultures that produced them. 
References

Bartholomae, D., \& Petrosky, A. (1986). Facts, artifacts, and counterfacts: Theory and method for a reading and writing course. Portsmouth, $\mathrm{NH}$ : Boynton/Cook.

Bloom, B. S. (1956). Taxonomy of educational objections: The classification of educational goals. New York, NY: Longmans, Green.

Camfield, E. K. (2016). Mediated-efficacy: Hope for "helpless" writers. Journal of Developmental Education, 39(3), 2-6.

Cho, J., \& Trent, A. (2005). "Backward" curriculum design and assessment: What goes around comes around, or haven't we seen this before? Taboo: The Journal of Culture and Education, 9(2), 105-122. Retrieved from https://files.eric.ed.gov/fulltext/EJ795704.pdf

Hepner, F. (1996). Interdisciplinary classes. Retrieved from https://files.eric.ed.gov/ fulltext/ED397872.pdf

Lane, J. A. (2015). The imposter phenomenon among emerging adults transitioning into professional life: Developing a grounded theory. Adultspan Journal, 14(2), 114-128. https://doi.org/10.1002/adsp.12009

Lesley, M. (2003). Exploring the links between critical literacy and developmental reading. In N. A. Stahl \& H. Boylan (Eds.), Teaching developmental reading: Historical, theoretical, and practical background readings (pp. 7286). Boston, MA: Bedford/St. Martin's.

Marzano, R. J., \& Kendall, J. (2008). Designing \& assessing educational objectives: Applying the new taxonomy Thousand Oaks, CA: Corwin Press.

Perkins, D. (2009). Making learning whole: How seven principles of teaching can transform education. San Francisco, CA: Jossey-Bass.

Perry, W. G. (1999). Forms of ethical and intellectual development in the college years: $A$ scheme. San Francisco, CA: Jossey Bass.

Pruett, P. S., \& Absher, B. (2015). Factors influencing retention of developmental education students in community colleges. Delta Kappa Gamma Bulletin, 81(4), 32-40.

Rosenblatt, L. (2005). Making meaning with texts. Portsmouth, NH: Heinemann.

Saxon, D. P., Martirosyan, N. M., \& Vick, N. T. (2016). NADE members respond: Best practices and challenges in integrated reading and writing, Part 1. Journal of Developmental Education, 39(2), 32-34.

Seidlitz, J., \& Perryman, B. (2011). Seven steps to a language-rich interactive classroom: Researched based strategies for engaging all students. San Clemente, CA: Canter.
Stanny, C. J. (2016). Reevaluating bloom's taxonomy: What measurable verbs can and cannot say about student learning. Education Sciences, 6(4), 37. https://doi.org/10.3390/ educsci6040037

Texas Higher Education Coordinating Board (2018). Developmental education update and 2018-2023 statewide plan for supporting underpreparedstudents. Retrievedfromhttp:// www.thecb.state.tx.us/reports/PDF/12271. PDF?CFID $=95582277 \&$ CFTOKEN $=84379529$

Texas Higher Education Coordinating Board (2019). Texas public higher education almanac. Retrieved online from http://www.thecb. state.tx.us/almanac 